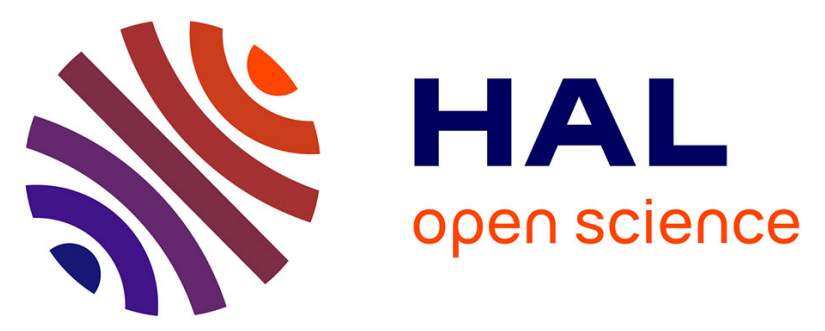

\title{
New Features and Uncovered Benefits of Polycrystalline Magnetite as Reusable Catalyst in Reductive Chemical Conversion
}

Sungjun Bae, Suji Gim, Hyungjun Kim, Vincent Dorcet, Mathieu Pasturel, Jean-Marc Greneche, Gopala Krishna Darbha, Khalil Hanna

\section{To cite this version:}

Sungjun Bae, Suji Gim, Hyungjun Kim, Vincent Dorcet, Mathieu Pasturel, et al.. New Features and Uncovered Benefits of Polycrystalline Magnetite as Reusable Catalyst in Reductive Chemical Conversion. Journal of Physical Chemistry C, 2017, 121 (45), pp.25195-25205. 10.1021/acs.jpcc.7b08178 . hal-01659405

\section{HAL Id: hal-01659405 \\ https://hal-univ-rennes1.archives-ouvertes.fr/hal-01659405}

Submitted on 11 Jan 2018

HAL is a multi-disciplinary open access archive for the deposit and dissemination of scientific research documents, whether they are published or not. The documents may come from teaching and research institutions in France or abroad, or from public or private research centers.
L'archive ouverte pluridisciplinaire HAL, est destinée au dépôt et à la diffusion de documents scientifiques de niveau recherche, publiés ou non, émanant des établissements d'enseignement et de recherche français ou étrangers, des laboratoires publics ou privés. 


\section{New Features and Uncovered Benefits of}

\section{Polycrystalline Magnetite as Reusable Catalysts in}

\section{Reductive Chemical Conversion}

Sungjun Bae, ${ }^{* a}$ Suji Gim, ${ }^{\mathrm{b}}$ Hyungjun Kim, ${ }^{\mathrm{b}}$ Vincent Dorcet, ${ }^{\mathrm{c}}$ Mathieu Pasturel, ${ }^{\mathrm{c}}$ Jean-Marc Grenèche, ${ }^{\mathrm{d}}$ Gopala Krishna Darbha, ${ }^{\mathrm{e}, \mathrm{f}}$ Khalil Hanna ${ }^{* \mathrm{~g}}$

\footnotetext{
a Department of Environmental Engineering, Konkuk University, 120 Neungdong-ro, Gwangjin-gu, Seoul 05029, Republic of Korea

${ }^{\mathrm{b}}$ Graduate School of Energy, Environment, Water, and Sustainability (EEWS), Korea Advanced Institute of Science and Technology, 291 Daehak-ro, Yuseong-Gu, Daejeon 305701, Republic of Korea

'Institut des Sciences Chimiques de Rennes, UMR CNRS 6226, 263 avenue Général Leclerc, 35042 Rennes Cedex 7, France

${ }^{\mathrm{d}}$ Institut des Molécules et Matériaux du Mans, UMR CNRS 6283, Université du Maine, 72085 Le Mans Cedex 9, France

${ }^{\mathrm{e}}$ National Institute of Technology - Andhra Pradesh, Tadepalligudem, Andhra Pradesh, 534101, India

${ }^{\mathrm{f}}$ Institut fur Nukleare Entsorgung (INE), Karlsruhe Institute of Technology (KIT), P.O. Box 3640, 76021 Karlsruhe, Germany

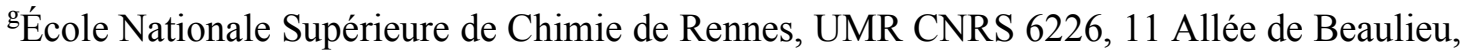
35708 Rennes Cedex 7, France

*Co-corresponding authors: Tel.: +82 $24503904,+33223238027$

E-mail address: bsj1003@konkuk.ac.kr (S. Bae), khalil.hanna@ensc-rennes.fr (K. Hanna)
}

Journal of Physical Chemistry C

September, 2017 


\begin{abstract}
Magnetite is one of the most well characterized and facilitated iron oxide in a variety of research and industrial fields. Especially, its easy separation by magnetism has attracted a great attention to use as a support material for various noble metallic catalysts. Here, we report for the first time that bare polycrystalline magnetite can show a remarkable catalytic activity toward $p$-nitrophenol reduction by sodium borohydride, while other three singlecrystal magnetite exhibit little effect on the catalysis. Electron and atomic force microscopies and Mössbauer spectroscopy showed that elemental Fe nanoparticles were formed on the surface of polycrystalline magnetite. Density functional theory calculation further elucidated that the $\mathrm{Fe}$ atom exposed at the high-index magnetite surface develops a significant $\mathrm{Fe}-\mathrm{BH}_{3}$ interaction and its leaching-out process can be substantially promoted. Surprisingly, recycling tests showed that this great activity could be fully preserved up to 10 reaction cycles, in contrast to the other noble metal-based catalysts showing a decrease in the catalytic activity as the reaction cycle increased.
\end{abstract}




\section{Introduction}

Catalytic reactions have been extensively applied to over $90 \%$ of all chemical manufacturing, contributing thus at around $35 \%$ of the world's gross domestic product. ${ }^{1}$ Especially, homogenous catalysts are commonly used for production of fine chemicals and pharmaceuticals. However, some drawbacks limit the reuse of catalysts due to contamination with final products and formation of metal complexes. ${ }^{2}$ In contrast, heterogeneous catalysts have attracted much attention in the catalysis processes for the past few decades because of their advantages such as well-defined structural materials, easy handling, and simple solidliquid separation. ${ }^{1,2}$ Heterogeneous catalysts produce around $95 \%$ of bulk chemicals and 3-5\% of fine chemicals (accounting $20 \%$ of profit). ${ }^{2}$

In heterogeneous catalysis, a variety of noble metals (e.g., $\mathrm{Au}, \mathrm{Pt}, \mathrm{Pd}$, and $\mathrm{Ag}$ ) are widely used for effective catalytic reactions and usually immobilized on other supports (e.g., carbon materials, polymers, and metal oxides) to prevent the loss of the noble metals after the catalytic reactions. ${ }^{3-9}$ Among the support materials, many types of iron oxides such as $\mathrm{FeO}$ (wüstite), $\gamma-\mathrm{Fe}^{3+}{ }_{2} \mathrm{O}_{3}$ (maghemite), $\alpha-\mathrm{Fe}^{3+}{ }_{2} \mathrm{O}_{3}$ (hematite) have been successfully used to develop efficient, low-cost, and recyclable supported catalysts for organic and inorganic transformation for the past few decades. ${ }^{10-13}$ In particular, magnetite $\left(\mathrm{Fe}^{2+}{ }_{1} \mathrm{Fe}^{3+}{ }_{2} \mathrm{O}_{4}\right)$, a facecentered cubic unit cell containing the $\mathrm{Fe}^{3+}$ ion in tetrahedral sites and both $\mathrm{Fe}^{3+}$ and $\mathrm{Fe}^{2+}$ ions in octahedral sites with $32 \mathrm{O}^{2-}$ ions, has shown an outstanding applicability not only in solidsupported catalysis but also in other-disciplinary research (e.g., semiconductor, magnetic resonance imaging, pigment, biomedicine, drug delivery, and environmental remediation $)^{2,14,15}$ due to its unique magnetic properties and easy manipulation for control of morphologies, particle size, and $\mathrm{Fe}^{2+} / \mathrm{Fe}^{3+}$ stoichiometry. ${ }^{12,15-19}$ However, determination of magnetite compositions which is highly sensitive to the preparation conditions is not a trivial task, particularly for nanoscale particles with a higher surface-to-volume ratio. ${ }^{20}$ Indeed, magnetite compositions range, without modification of crystal structure, from that of 
stoichiometric $\mathrm{Fe}_{3} \mathrm{O}_{4}$, with $8 \mathrm{Fe}^{3+}$ ions in tetrahedral and $8 \mathrm{Fe}^{2+}+8 \mathrm{Fe}^{3+}$ ions in octahedral sites, to that of maghemite $\gamma-\mathrm{Fe}_{2}^{\mathrm{III}}{ }_{2} \mathrm{O}_{3}$ (considered as an extreme example of a nonstoichiometric magnetite) with only $\mathrm{Fe}^{3+}$ ions in both tetrahedral and octahedral sites. ${ }^{21}$

Sodium borohydride $\left(\mathrm{NaBH}_{4}\right)$ induced p-nitrophenol ( $p$-NP) reduction to paminophenol ( $p$-AP), is perhaps the most widely used catalytic model reactions to check the catalytic activity of the heterogeneous catalysts. ${ }^{22-29}$ Indeed, a large number of studies has struggled to develop novel magnetite-supported catalysts using different materials such as $\mathrm{Ag}$, $\mathrm{Au}, \mathrm{Ag}-\mathrm{SiO}_{2}, \mathrm{Cu}$-graphene, $\mathrm{SiO}_{2}-\mathrm{CeO}_{2}, \mathrm{Co}-\mathrm{Se}$, and $\mathrm{Pt}-\mathrm{Pd}$ and proved their remarkable catalytic activity for $p$-NP reduction..$^{5,6,8,23-28}$ In the previously reported studies, control experiments using bare magnetite $(<300 \mathrm{~nm})$ have normally shown little effect on the catalytic activity, indicating that magnetite itself does not possess any catalytic activity but only acts as a support during the catalysis. ${ }^{5,6,28}$ On the other hand, our recent findings showed that magnetite can provide the reactive surface for $\mathrm{p}-\mathrm{NP}$ reduction in $\mathrm{NaBH}_{4}$ induced catalytic reaction $^{30}$ which is contrary to those known already. This may be because the catalytic activity of magnetite in $\mathrm{NaBH}_{4}$ induced catalytic reaction may be dependent on the physical and chemical properties of bare magnetite. However, a limited knowledge has been provided for understanding of interaction between different type of magnetite and $\mathrm{NaBH}_{4}$ and its potential application to reductive transformation of organic compounds to date.

Here, we report for the first time that important reduction of $p$-NP using bare magnetite without precious noble metals can be achieved, but this reactivity is strongly dependent on surface and structure properties of magnetite. The main objectives of this study were to (i) examine the reaction of four different magnetite during the $\mathrm{NaBH}_{4}$ induced $p$-NP reduction, (ii) investigate the catalytic reaction mechanism at molecular level supporting by a variety of surface analysis and theoretical study (i.e., density functional theory (DFT) calculation), and (iii) find out a feasibility to use magnetite as an effective, durable, economical, and 
manageable catalytic material without using expensive noble metals widely used in heterogeneous catalysis.

\section{Experimental Methods}

Materials and chemicals. Four different sizes of lab-synthesized and commercial magnetite were prepared for this study. Magnetite $1(\mathrm{M} 1,10-20 \mathrm{~nm})$ and $2(\mathrm{M} 2,50-200 \mathrm{~nm})$ were differently synthesized by $\mathrm{Fe}(\mathrm{II})$ induced transformation from ferrihydrite ${ }^{31}$ and coprecipitation method using $\mathrm{Fe}(\mathrm{II})$ and Fe(III) solutions. Magnetite $3(\mathrm{M} 3,100-500 \mathrm{~nm})$ and 4 (M4, $100 \mathrm{~nm}-10 \mu \mathrm{m}$ ) were purchased from Aldrich Chemical Co. and Prolabo Co., respectively. Chemicals used in the experiment were ferric chloride (98\%, Sigma), ferrous sulfate $(99 \%$, Sigma), $p$-NP ( $>99 \%$, Sigma), $p$-aminophenol ( $p$-AP) ( $>98 \%$, Sigma), sodium hydroxide (95\%), and sodium borohydride (99\%, Sigma). Acetonitrile (HPLC grade, J.T.Baker, USA) and acetic acid (99.7\%, ACROS) were used for mobile phase of high performance liquid chromatography (HPLC). All experiments were prepared using deionized water (DIW), prepared using ultra-pure water $(18 \mathrm{M} \Omega \cdot \mathrm{cm})$.

Catalytic reduction of $\mathbf{p - N P}$ by magnetite. The reduction of $p$-NP by four different magnetite samples was carried out in the presence of $100 \mathrm{mM} \mathrm{NaBH}_{4}$. An exact amount of magnetite $(3 \mathrm{mg})$ was added into a quartz cuvette containing $2.7 \mathrm{~mL}$ of the $\mathrm{NaBH}_{4}$ solution $(100 \mathrm{mM})$ and $0.3 \mathrm{~mL}$ of $p$-NP $(1 \mathrm{mM})$ in $\mathrm{NaBH}_{4}$ solution $(100 \mathrm{mM})$ to initiate the reduction of $p$-NP. The total volume of reaction mixture was thus $3 \mathrm{~mL}$ with initial concentrations of 1 $\mathrm{g} / \mathrm{L}$ magnetite and $0.1 \mathrm{mM} p$-NP, respectively. The concentration of $p$-NP was measured at $400 \mathrm{~nm}$ wavelength by UV-vis spectrophotometer (CARY 50 probe, Varian). To investigate the effect of $\mathrm{NaBH}_{4}$ concentration on the catalytic activity of M4, other four different concentrations of $\mathrm{NaBH}_{4}(10,25,50$, and $200 \mathrm{mM})$ were used for the reduction of $p$-NP. A recycling test (10 times) was also conducted using M4. After finishing the reduction of $p$-NP, 
magnetite used was magnetically collected at the bottom of the cuvette by removal of aqueous solution, then washed three times with DIW to remove the residual $p$-AP and finally, $\mathrm{NaBH}_{4}$ $(2.7 \mathrm{~mL})$ and $p$-NP $(0.3 \mathrm{~mL})$ were added into the quartz cuvette for recycling test.

HPLC analysis and Fe and $\mathrm{H}_{2}$ measurements. The final concentrations of $p$-NP and $p$-AP in aqueous solution were confirmed by HPLC (Waters) equipped with a C18 packed column (Waters) and UV detector. An exact amount of aqueous sample $(2.0 \mathrm{~mL})$ was collected by a sterilized disposable syringe after finishing the catalysis experiment. Then, the sample was filtered through a $0.2-\mu \mathrm{m}$ membrane filter and $1 \mathrm{~mL}$ of the filtered sample was transferred into HPLC auto-sampler vials. The concentrations of $p$-NP and $p$-AP were quantified at wavelengths of 317 and $273 \mathrm{~nm}$ at a flow rate of $1.0 \mathrm{~mL} \mathrm{~min}{ }^{-1}$. A mixture of $49.5 \%$ DIW, $49.5 \%$ acetonitrile, and $1 \% \mathrm{CH}_{3} \mathrm{COOH}$ was used for the mobile phase.

$\mathrm{Fe}^{2+}$ and $\mathrm{Fe}^{3+}$ contents for each magnetite were measured by the ferrozine method using an UV-vis spectrophotometer. Magnetite was fully dissolved in $6 \mathrm{M} \mathrm{HCl}$ deaerated by $\mathrm{N}_{2}$, then the amounts of $\mathrm{Fe}^{2+}$ were measured at the wavelength of $562 \mathrm{~nm} .{ }^{32}$ The total $\mathrm{Fe}$ was also measured by adding $10 \%$ hydroxylamine solution. Fe(III) concentration was calculated by subtracting $\mathrm{Fe}(\mathrm{II})$ concentration from the total $\mathrm{Fe}$ concentration. The concentration of dissolved $\mathrm{Fe}^{2+}$ was not significant in membrane-filtered samples, indicating that the $\mathrm{Fe}$ dissolution from magnetite can be considered as negligible in this study.

The contents of $\mathrm{H}_{2}, \mathrm{O}_{2}$, and $\mathrm{N}_{2}$ in the magnetite- $\mathrm{NaBH}_{4}$ suspension were measured by a gas chromatograph (GC, Shimadzu 8A) equipped with a thermal conductivity detector and a 2-m stainless column packed with Porapak Q (50/80 mesh). An exact amount of magnetite (3 $\mathrm{mg}$ ) was transferred to serum bottles (total volume: $21.9 \mathrm{~mL})$ containing $3 \mathrm{~mL}$ of $\mathrm{NaBH}_{4}(100$ $\mathrm{mM})$. Headspace sampling was conducted and $1 \mathrm{~mL}$ of gas samples were introduced into the injection port by a gastight syringe. We measured the amount of each gas in head space and re-calculated the percentage value of each gas in total amount. The operational temperatures 
of the injection port, the oven and the detector were 100,70 and $100^{\circ} \mathrm{C}$, respectively. Helium was used as the carrier gas at a flow rate of $30 \mathrm{ml} \cdot \mathrm{min}^{-1}$

Surface characterization. The morphological change of magnetite was identified by transmission electron microscopy (TEM) using JEM-2100 (JEOL) microscope working at 200 $\mathrm{KV}$ equipped with a scanning module and with an energy dispersive X-ray detector (Oxford) for elemental mapping analysis and by scanning electron microscopy (SEM) using JSM7100F (JEOL). The samples before and after the reaction with $\mathrm{NaBH}_{4}$ were transferred into an anaerobic chamber (JACOMEX) to avoid the oxidation of magnetite by $\mathrm{O}_{2}$ and washed twice with deaerated ethanol. The magnetite suspensions in ethanol phase were stored in the anaerobic chamber prior to their use for electron microscopy. For TEM analyses, one droplet of the diluted magnetite suspension was put on $\mathrm{Cu}$ grids. For SEM analysis, the magnetite suspension was deposited on a carbon tape and the samples analyzed by SEM.

The quantity of iron phases, unit-cell lengths, and average crystallite size for each magnetite before and after the reaction with $\mathrm{NaBH}_{4}$ were obtained by Le Bail or Rietveld refinement of X-ray diffraction (XRD) patterns (D8 Advance, BRUKER). The magnetite suspensions prepared in ethanol phase were used for XRD analysis. The suspensions were transferred to XRD holder and dried for $1 \mathrm{~h}$ in the anaerobic chamber. The dried samples were treated with 1:1 (V:V) glycerol solution to avoid the oxidation of magnetite samples during the XRD measurement. ${ }^{29,33}$ XRD patterns were collected in a modified Bragg-Brentano $\theta-2 \theta$ geometry goniometer working with a $\mathrm{Ge}(111)$ monochromatized $\mathrm{Cu} \mathrm{K} \alpha 1$ radiation $(\lambda=$ $1.5406 \AA$ ) and scanned between $10^{\circ}$ and $80^{\circ}$ with steps of $0.02^{\circ}$ and integration time of $179 \mathrm{~s}$ $\operatorname{step}^{-1}$. The diffractometer is equipped with a LynxEye fast detector enabling the removal of iron fluorescence signal. The iron phases were identified by matching XRD patterns of each sample with the Joint Committee on Powder Diffraction Standards diffraction data files (JADE 9, Materials Data, Inc.). Le Bail and Rietveld refinements were performed using the 
Fullprof program. ${ }^{34}$ The crystallite size was determined from the previous refinements by fitting the lorentzian broadening of the diffraction peaks using a Thompson-Cox-Hastings peak profile function and taking into account the instrumental resolution function. ${ }^{35}$

Atomic force microscopy (AFM) is a powerful technique to characterize the morphology of nanoparticles at high resolution $(\sim \mathrm{nm}$ scale). Herein, AFM (Digital Instruments Dimension 3100 equipped with nanoscope IV controller) was applied to study the change in topography of M4 in the absence and presence of $\mathrm{NaBH}_{4}(100 \mathrm{mM})$. A droplet of magnetite suspension was placed on a freshly cleaved biotite substrate and allowed to dry before measurement. The experiments were performed in contact mode with a cantilever of spring constant $0.35 \mathrm{~N} / \mathrm{m}$ (SNL-10, Bruker AFM probes). The obtained images are processed in Scanning Probe Image Processing (SPIP) software (Image metrology) applying the line profile analysis.

${ }^{57} \mathrm{Fe}$ Mössbauer spectra were obtained at 300 and $77 \mathrm{~K}$ using a conventional constant acceleration transmission spectrometer with a ${ }^{57} \mathrm{Co}(\mathrm{Rh})$ source. The samples resulting from drying solutions are containing about $5 \mathrm{mg} / \mathrm{cm}^{2}$. They were located in a bath cryostat for low temperature measurements. The spectra were fitted by means of the MOSFIT program involving quadrupolar doublets and/or magnetic sextets, both composed of Lorentzian lines. The relative proportions of these Fe species are estimated from the corresponding absorption areas, assuming thus the same values of their recoilless Lamb-Mössbauer factors. An $\alpha$-Fe foil was used as calibration sample while the values of isomer shift are quoted relative to that of $\alpha-\mathrm{Fe}$ at $300 \mathrm{~K}$.

Computational Method. We performed DFT calculations by using the Vienna Ab-initio Software Package (VASP) program $^{36}$ with Perdew-Burke-Emzerhof (PBE) exchangecorrelation functional. ${ }^{37}$ We investigated four slab models of magnetite; $(2 \times 1) \mathrm{Fe}_{3} \mathrm{O}_{4}(111)$, 
$(2 \times 2) \mathrm{Fe}_{3} \mathrm{O}_{4}(220),(2 \times 3) \mathrm{Fe}_{3} \mathrm{O}_{4}(311),(3 \times 1) \mathrm{Fe}_{3} \mathrm{O}_{4}(400),(4 \times 1) \mathrm{Fe}_{3} \mathrm{O}_{4}(422)$ and $(8 \times 1)$

$\mathrm{Fe}_{3} \mathrm{O}_{4}(511)$ surface, where bottom $1 / 3$ layer was kept as fixed at a lattice point whereas the upper layers were allowed to be fully relaxed (Figure S1). To prevent the interaction between imaginary slab models along z-direction due to the periodic boundary condition, a vacuum slab of $\sim 20 \AA$ perpendicular to the magnetite surface was included in the simulation cell. An energy cutoff of $400 \mathrm{eV}$ was used for the plane wave basis set and only the Gamma point was sampled in the reciprocal space.

\section{Results and Discussion}

Characterization of magnetite. Morphological information for each magnetite (M1, M2, M3, and M4) and their mineral identity were analyzed by TEM-selected area electron diffraction (SAED) and SEM. Figure 1a and S2a show a spherical shape of M1 in the range of 10-20 nm. The SAED pattern for M1 (Figure 1b) shows discontinuous circles which diameters correspond to crystallographic planes of magnetite, i.e., 111, 220, and 311. The XRD pattern of M1 (Figure S3) is indexed within the magnetite structure (space group $F d \overline{3} m, a=8.3640(6)$ $\AA$ ). The average crystallite size analyzed by XRD was $13 \mathrm{~nm}$ (Table S1), which are in good agreement with TEM results. Ideal magnetite has a $\mathrm{x}=0.5$ ratio of $\mathrm{Fe}^{2+} / \mathrm{Fe}^{3+}$ stoichiometry but it becomes easily oxidized to nonstoichiometric magnetite $(x<0.5)$ by exposure to $\mathrm{O}_{2}$ and other oxidants in surrounding environment. The $\mathrm{Fe}^{2+} / \mathrm{Fe}^{3+}$ ratio for $\mathrm{M} 1$ using complete acid dissolution was 0.19 (Table S2), being close to the $\mathrm{Fe}^{2+} / \mathrm{Fe}^{3+}$ ratio $(\mathrm{x}=0.2)$ estimated by the unit-cell length $(\mathrm{a}=8.3640(6))$ using a linear interpolation between $\mathrm{Fe}^{2+} / \mathrm{Fe}^{3+}$ stoichiometry and reference unit-cell lengths. ${ }^{38}$ Due to its very small particle size, the non-stoichiometry character (or the partial oxidation) of M1 was expected, but accurate identification of magnetite and maghemite in M1 cannot properly performed based only on XRD. ${ }^{39}$ Mössbauer spectroscopy can however provide relevant information on both the valency and spin states of 
Fe species together with magnetic properties from the analysis of the hyperfine parameters. The magnetic sextet with broadened and asymmetrical and a central quadrupolar component observed in 300K Mössbauer spectrum of M1 (Figure S4) are characteristics of $\mathrm{Fe}^{3+}$ species, attributed to ultrafine maghemite nanoparticles and larger single domain ones with slow superparamagnetic relaxation phenomena. The latter behavior can be expected based on the particle size previously estimated from X-ray patterns, and suggests a significant oxidation of M1 nanoscale particles.

M2 shows a cubic morphology with particle sizes of 50-400 nm (Figures 1c and S2b) and its SAED pattern (Figure 1d) is assigned to magnetite. The $\mathrm{Fe}^{2+} / \mathrm{Fe}^{3+}$ ratios for M2 were $x$ $=0.47(\mathrm{HCl}$ dissolution) and $0.54(\mathrm{XRD})$, suggesting that $\mathrm{M} 2$ is the closest sample to the magnetite stoichiometry in the present study. Higher than $x=0.5$ ratio for M2 (XRD) may be caused by the uncertainty of the linear interpolation in XRD analysis and $\mathrm{HCl}$ dissolution method $\left(\mathrm{R}^{2}=0.92\right),{ }^{38}$ but still valuable to estimate the $\mathrm{Fe}^{2+} / \mathrm{Fe}^{3+}$ ratio. The average crystallite size for M2 was $46 \mathrm{~nm}$ from XRD data. The larger particle and crystallite sizes for M2 compared to M1 could explain the higher resistance to oxidation and thus the higher $\mathrm{x}$ value.

M3 shows the mixture of non-uniform and cubic particles in the range of 100-500 nm (Figures 1e and S2c). We observed that M3 contains some oxidized mineral form recognized by the reflection 110 (i.e., maghemite) and a spot indicated by g (i.e., goethite, $\alpha$-FeOOH) in its SAED pattern (Figure 1f). This implies that traces of the completely oxidized form not detected by XRD could be present in M3 due to the detection limit of the XRD analysis (1$2 \%$ ). The $\mathrm{Fe}^{2+} / \mathrm{Fe}^{3+}$ ratios for $\mathrm{M} 3$ were $x=0.42(\mathrm{HCl}$ dissolution) and $0.48(\mathrm{XRD})$ and the average crystallite size for M3 was $45 \mathrm{~nm}$.

M4 has distinct characteristics from other three magnetite. TEM and SEM images for M4 show heterogeneous particle sizes $(100 \mathrm{~nm}-10 \mu \mathrm{m})$ with non-uniform shapes (Figures $1 \mathrm{~g}$ and $\mathrm{S} 2 \mathrm{~d}$ ). The $\mathrm{Fe}^{2+} / \mathrm{Fe}^{3+}$ ratios for M4 were $x=0.44$ ( $\mathrm{HCl}$ dissolution) and 0.48 (XRD). Interestingly, the average crystallite size was $54 \mathrm{~nm}$, which is much smaller than particle sizes 
observed by TEM and SEM. This indicates that M4 particles are polycrystalline. AFM topographic images clearly shows that lateral fluctuations of surface features can be detected in almost every $100 \mathrm{~nm}$ distance with $1-6 \mathrm{~nm}$ of topography deviation (Figure S5), confirming that M4 particles are made of polycrystalline structured magnetite without preferred orientated single crystals. Nevertheless, the relatively large particle and crystallite sizes enable to isolate single crystalline domains and SAED pattern analysis clearly shows individual spots corresponding to the $\overline{1} 12$ zone axis of magnetite (Figure $1 \mathrm{~h}$ ).

As in case of magnetite, the Mössbauer spectra of M2, M3, and M4 can be described by means of two components attributed to $\mathrm{Fe}^{3+}$ and $\mathrm{Fe}^{2.5+}$ species, whereas the mean value of the isomer shift is smaller suggesting some partial oxidation of magnetite. The hyperfine structures can be decomposed into two ideal components corresponding to magnetite and maghemite components (red and blue, respectively) (Figure S4). The estimates resulting from their relative absorption area were 93:7, 70:30, and 83:17 for M2, M3, and M4 respectively, which are rather in good agreement with the order of the $\mathrm{Fe}^{2+} / \mathrm{Fe}^{3+}$ ratio $(\mathrm{M} 2>\mathrm{M} 4>\mathrm{M} 3)$ (Table S2). Finally, the results obtained from BET shows the typical trend, i.e. decrease in surface area from 75 to $1.7 \mathrm{~m}^{2} \mathrm{~g}^{-1}$ with respect to the increase in particle size from M1 to M4 (Table S2).

Reduction of $p$-NP to $p$-AP by magnetite-NaBH ${ }_{4}$ system. The catalytic properties of each magnetite sample were investigated using the reduction of $p$-NP to $p$-AP by $\mathrm{NaBH}_{4}$ as a model reaction (Figure S6). No significant reduction of $p$-NP was observed by $\mathrm{NaBH}_{4}$ solution $(100 \mathrm{mM})$, indicating that $\mathrm{NaBH}_{4}$ alone cannot reduce $p$-NP under our experimental conditions. In addition, all magnetite did not show any reduction of $p$-NP to $p$-AP without addition of $\mathrm{NaBH}_{4}$, indicating that each magnetite does not directly reduce $p$-NP without $\mathrm{NaBH}_{4}$ in this study. The initial absorption peak of $p$-NP $(317 \mathrm{~nm})$ under acid and neutral conditions was shifted to $400 \mathrm{~nm}$ after addition of $\mathrm{NaBH}_{4}$ due to the formation of $p$ - 
nitrophenolate ions under basic condition $(\mathrm{pH}>11) .{ }^{8}$ We did not observe any significant change in the UV-vis spectra of M1, M2, and M3 suspensions after $120 \mathrm{~min}$. TEM and SEM images after the reaction of M1 revealed morphological changes in magnetite structure, resulting in the non-uniformed shape of bigger particles than that of original M1 (Figure S7ad), while other M2 and M3 did not show any morphological change after the reaction (Figure S7e-1). However, the morphological change of M1 does not seem to influence the catalytic activity of M1 toward $p$-NP.

In contrast, M4 showed a remarkable decrease of the peak intensity at $400 \mathrm{~nm}$ together with an increase of a new peak at $300 \mathrm{~nm}$ (Figure S6), which can be attributed to $p$-AP. ${ }^{23,40}$ Based on the decrease in peak intensity at $400 \mathrm{~nm}$ (Figure S8), we can estimate that almost 70\% of initial $p$-NP was reduced after 120 minutes. This estimation was confirmed by HPLC measurement after the reaction showing almost $62 \%$ of $p$-NP conversion with $70 \%$ of $p$-AP production. This indicates that only M4 has an excellent catalytic activity toward the $p$-NP reduction by $\mathrm{NaBH}_{4}$. The catalytic activity that is closely related to the $\mathrm{NaBH}_{4}$ concentration showed acceleration of $p$-NP reduction as the $\mathrm{NaBH}_{4}$ concentration increased from 0 to 200 $\mathrm{mM}$ (Figure 2a). In particular, an induction time until 20 min was observed before initiating the $p$-NP reduction and a linear decrease of the absorbance at $400 \mathrm{~nm}$ with increasing time (Figure 2a), indicating pseudo-zero-order reduction kinetics. Furthermore, the zero-order reduction kinetics seems proportional to the increase in $\mathrm{NaBH}_{4}$ concentration (Figure $2 \mathrm{~b}$ ). This result differs from that normally observed on various noble metallic catalysts showing pseudo-first-order reduction kinetics without the presence of induction time. ${ }^{5,24,26}$ The induction time has been observed in the presence of carbon materials (e.g., graphene and natural polymer dextran) for the initial period for $p$-NP adsorption on the active sites of carbon materials ${ }^{40,41}$ or in nanomaterials for a surface restructuring before the catalytic reaction starts. ${ }^{42}$ Because more than $95 \%$ of conversion of $p$-AP from $p$-NP was achieved by HPLC analysis, adsorption of $p$-NP on M4 can be considered as negligible. Furthermore, the 
surface restructuring reaction is very fast, usually takes within $20 \mathrm{~s}$ not until $20 \mathrm{~min},{ }^{42}$ ruling out such a phenomenon in our case. Moreover, no correlation between the catalytic activity of magnetite and physicochemical properties such as particle size, BET or $\mathrm{Fe}^{2+} / \mathrm{Fe}^{3+}$ ratio was observed. Therefore, other factors must undoubtedly control the catalytic reduction of $p$-NP on the surface of M4.

Catalysis mechanism in magnetite- $\mathrm{NaBH}_{4}$ suspension. Electron microscopy and AFM analysis were conducted to investigate the catalysis mechanism during the reaction of M4 with $\mathrm{NaBH}_{4}$. Interestingly, we observed the formation of new aggregates of nanoparticles and their attachment on M4 surface after reaction with $\mathrm{NaBH}_{4}$ (Figure 3a). The magnified TEM images (Figure 3c and d) clearly illustrated the spherical shape of the nanoparticles with $<50$ nm diameter, which have amorphous SAED patterns with no clear lattice fringes and diffuse rings likely elemental Fe nanoparticles (Figure $3 b$ ). ${ }^{43}$ This is apparently different from the typical SAED patterns of unreacted magnetite (Figure 3e). EDX mapping confirmed that new nanoparticles mostly consist of $\mathrm{Fe}$ and $\mathrm{O}$, without $\mathrm{Na}$ and $\mathrm{B}$ (Figure 3f), indicating that M4 formed Fe-based nanoparticles after the reaction with $\mathrm{NaBH}_{4}$. SEM imaging also showed a cauliflower structure on the surface of M4 (Figure S9a). Consequently, the formation of elemental Fe nanoparticles on M4 surfaces after reaction with $\mathrm{NaBH}_{4}$ may explain the great catalytic activity of M4, as we have recently observed for synthetic zero valent iron in the presence of $\mathrm{NaBH}_{4}{ }^{29}$

In addition, the formation of cracks on the M4 surface was observed after the reaction (Figure S9b). AFM surface images of microscale M4 before (Figure 4a) and after (Figure 4b) the addition of $\mathrm{NaBH}_{4}$ strongly supports the dramatic surface changes observed at different scales by both SEM and TEM. A relatively smooth surface of pristine M4 (Figure 4c) was significantly changed to be highly rough in a macroscale point of view (Figure 4d). The direct comparison of topography deviation with and without $\mathrm{NaBH}_{4}$ clearly shows the evolution of 
spikes (i.e., Fe nanoparticles) with the formation of deep macroscopic crack (approximately $125 \mathrm{~nm}$ with reference to the non-reacted surface plane) on the surface of M4. To investigate the more precise formation mechanism of elemental Fe nanoparticles, high resolution (HR) TEM was conducted using $6 \mathrm{~h}$ reaction sample with $\mathrm{NaBH}_{4}$ without $p$-NP (Figure 5). The formation of cracks on outer surfaces of M4 (Figure 5a) and nanoparticles possessing inner crystal lattices are observed. The SAED pattern of the inner crystal lattices revealed the magnetite peaks $311 \mathrm{~m}, 400 \mathrm{~m}$, and $422 \mathrm{~m}$, but we do not see the $222 \mathrm{~m}$ and $111 \mathrm{~m}$ peaks present on other crystallites. We thus suggest the presence of wüstite $(\mathrm{FeO})$ which $111 \mathrm{w}$ and $200 \mathrm{w}$ peaks are superimposed with $311 \mathrm{~m}$ and $400 \mathrm{~m}$, respectively, as these two peaks are most intense for this phase. This implies that wüstite could be intermediate phase in the reductive reaction of M4 to elemental Fe nanoparticles.

Although the formation mechanism of typical elemental Fe nanoparticles synthesized by $\mathrm{Fe}^{3+}-\mathrm{NaBH}_{4}$ solution system is unclear to date, it might involve the classic crystal formation caused by spontaneous formation of nuclei and their growth up to a critical size as normally observed in crystal formation from solution. ${ }^{44}$ Interestingly, the formation mechanism of elemental metallic Fe nanoparticles from $\mathrm{M} 4-\mathrm{NaBH}_{4}$ system seems to be as pre-nucleation cluster induced crystal formation. ${ }^{45}$ Hua and Huang have reported that microscale magnetite octahedra can be transformed to magnetite single crystal microplates by $\mathrm{NaBH}_{4}$ called in "chemical etching process". ${ }^{46}$ Here, we observe the formation of tiny nanoparticles and their aggregation giving rise to larger particles as evidenced by TEM and AFM (Figure S10a and c). Particle size analysis from AFM also reveals that the dominant size of particles without $\mathrm{NaBH}_{4}$ varied from $100-260 \mathrm{~nm}(64 \%)$ to larger size $<2 \mu \mathrm{m}$, while the sample with $\mathrm{NaBH}_{4}$ showed $63 \%$ of tiny nanoparticles $(<45 \mathrm{~nm})$ with other small sized nanoparticles $(<280 \mathrm{~nm})$ (Figure S10d). Furthermore, a monodisperse size distribution of tiny bead shaped nanoparticles (less than $2 \mathrm{~nm}$ ) was observed at outer layers (Figure $5 \mathrm{~b}$ and c), indicating that elemental Fe nanoparticles may form through the aggregation of nanometric building blocks. 
DFT calculation. It has been hypothesized that surface defects of magnetite (e.g., edge and corner sites, shallow walls of phase boundaries, and bridge between each single crystal), possibly less thermodynamically stable relative to the highly coordinated surface, may provide the specific reactive sites for $\mathrm{NaBH}_{4},{ }^{30}$ and thus explain the greater reactivity of magnetite. However, it is still unclear which surface index on magnetite is predominantly reacted with $\mathrm{NaBH}_{4}$. To investigate the surface index dependent activity of magnetite, we used DFT calculations in this study. The net reaction of $p$-NP reduction with $\mathrm{NaBH}_{4}$ in an alkaline aqueous solution is $p-\mathrm{NP}+3 \mathrm{NaBH}_{4}+\mathrm{H}_{2} \mathrm{O} \rightarrow p$-AP $+3 \mathrm{NaOH}+3 \mathrm{BH}_{3} .{ }^{30}$ Based on the well-known Bell-Evans-Polyanyi principle, ${ }^{47,48}$ the binding energy of $\mathrm{BH}_{3}$ to the magnetite surface $\left(\Delta \mathrm{E}_{\mathrm{b}}{ }^{\mathrm{BH} 3}\right)$ can be conceived as a good activity descriptor when the magnetite surface is involved in the reaction as a catalyst. Figure 6 shows DFT calculated $\Delta \mathrm{E}_{\mathrm{b}}{ }^{\mathrm{BH} 3}$ values for the most stable configuration of $\mathrm{BH}_{3}$ on the six different surface slab models of magnetite: (111), (220), (311), (400), (422), and (511). We found that the binding affinity becomes substantial generally for the high index surfaces, leading to a close interaction between $\mathrm{BH}_{3}$ and surface-exposed Fe. Particularly, Fe metals exposed on the (400) and (511) surfaces show the strongest interaction with $\mathrm{BH}_{3}$. We further calculated the electrochemical potential for leaching $\mathrm{Fe}$ out from the magnetite surface and forming an elemental $\mathrm{Fe}\left(\varepsilon_{\mathrm{Fe}}^{0}\right)$. The electrochemical reaction is written as following:

$$
\left(*-F e^{n+}\right)+n e^{-} \rightarrow(*-\square)+F e^{0}
$$

where $n$ means the number of electrons that is 3 , and the asterisk denotes the magnetite surface bound state. We calculated the reaction energy $(\Delta E)$ associated with above reaction (Eq. 1), which is approximated to the reaction free energy, $\Delta G \approx \Delta E$. We then calculated $\varepsilon_{\mathrm{Fe}}^{0}$ 
using Nernst equation; $\Delta G=-n F \varepsilon_{F e}^{0}$, and $\varepsilon_{F e}^{0}$ is referenced to $4.44 \mathrm{~V}$ to denote it versus standard hydrogen electrode (SHE). ${ }^{49}$ The results suggest that $\varepsilon_{F e}^{0}$ shows the same tendency to the change of $\Delta \mathrm{E}_{\mathrm{b}}{ }^{\mathrm{BH} 3}$ for various surfaces; higher reduction potential for high index surfaces. We further observed that $\varepsilon_{F e}^{0}$ of (400) and (511) surfaces increased up to $\sim 1 \mathrm{~V}$ compared to the most stable (111) surface. This indicates that Fe exposed at the high index magnetite surface can be much easily leached out to form an elemental Fe that can further be utilized for the p-NP reduction. We, therefore, anticipate that M4 may possess much high index surface at its surface defects, leading to the intensive interaction between the surface and $\mathrm{NaBH}_{4}$.

Catalytic activity and stability of polycrystalline magnetite. To assess the catalytic stability of polycrystalline magnetite in $\mathrm{NaBH}_{4}$ system, $p$-NP reduction (or $p$-AP production) was determined up to ten reaction cycles. The rationale of these experiments is two-fold: (i) compare the catalytic recyclability of M4 with other metallic catalysts, which normally shows deactivation as the number of reaction cycle increased ${ }^{5,8,28,50,51}$; and (ii) get better insights about the reaction kinetics and mechanisms.

Surprisingly, the reduction kinetics of $p$-NP was kept increasing significantly until $3^{\text {rd }}$ cycle and then reached a steady state (i.e. constant kinetic rate of $0.132 \mathrm{~min}^{-1}$ within the error value, Figure $7 \mathrm{a}$ and $\mathrm{b}$ ). We also observed the almost complete conversion of $p$-NP to $p$-AP by HPLC analysis after each reaction of $30 \mathrm{~min}$ (Figure 7c). It should be noted that the reduction kinetics seems to be changed from zero-order kinetics to first-order kinetics from $3^{\text {rd }}$ cycle $\left(R^{2}>0.95\right)$. This suggests that both formation of elemental Fe nanoparticles and subsequent catalytic reaction simultaneously proceeded during the $1^{\text {st }}$ and $2^{\text {nd }}$ cycles. The reduction kinetics of $p$-NP might be governed by the formation kinetics of elemental $\mathrm{Fe}$ nanoparticles, resulting in the zero-order-kinetics. After $3^{\text {rd }}$ cycle, the formation of elemental 
Fe nanoparticles may be terminated due to the limited surface of M4. Then the generated nanoparticles previously can continue the catalytic reduction of $p$-NP with a typical firstorder-kinetic without deactivation process up to 10 times recycle. To confirm both the enhanced catalytic activity during $1^{\text {st }}$ to $3^{\text {rd }}$ cycles and the constant catalytic activity after $3^{\text {rd }}$ cycle, the production of $\mathrm{H}_{2}$ was measured after $1^{\text {st }}, 3^{\text {rd }}, 5^{\text {th }}$, and $10^{\text {th }}$ cycles (Table S3). It is known that the production reaction of $\mathrm{H}_{2}$ from $\mathrm{NaBH}_{4}$ solution is exothermic $\left(\mathrm{NaBH}_{4}\right.$ $(-188.61 \mathrm{~kJ})+2 \mathrm{H}_{2} \mathrm{O}(-571.66 \mathrm{~kJ}) \rightarrow \mathrm{NaBO}_{2}(-977.0 \mathrm{~kJ})+4 \mathrm{H}_{2}(0 \mathrm{~kJ})$ at $\left.25{ }^{\circ} \mathrm{C}\right)$ and its reaction can be accelerated by catalysts. ${ }^{52}$ The percentage of $\mathrm{H}_{2}$ after $1^{\text {st }}$ cycle $(120 \mathrm{~min})$ was $29.8 \%$, which is almost similar to the control 1 (120 min reaction without M4), while its value significantly increased at $3^{\text {rd }}$ cycle $(42.6 \%)$ in $30 \mathrm{~min}$. This amount was 3.5 times higher than that of control 2 (30 min reaction without M4), underscoring the enhanced catalytic activity of M4 with $\mathrm{NaBH}_{4}$ solution. The $\mathrm{H}_{2}$ production at $5^{\text {th }}(43.2 \%)$ and $10^{\text {th }}(45.4 \%)$ cycles was very similar to the $3^{\text {rd }}$ cycle within the error values, confirming the constant catalytic activity of M4 after $3^{\text {rd }}$ cycle.

The 300K Mössbauer spectra of M4 submitted to several reaction cycles clearly showed changes growing at the central part of the spectra with the emergence of quadrupolar component which turns into a strongly broadened line (Figure 8). The proportion of this quadrupolar component (green line) is estimated at about $2 \%$ in M4 1 time, whereas the isomer shift value $(0.95 \mathrm{~mm} / \mathrm{s})$ suggests $\mathrm{Fe}^{2+}$ which could be attributed to non-stoichiometric $\mathrm{FeO}$ phase. The central quadrupolar component becomes more important in M4 $5^{\text {th }}$ times (estimated at about 10-12\%) but the isomer shift value is rather consistent with the presence of elemental metallic Fe. For the $10^{\text {th }}$ times sample, this component significantly increased up to about $30-35 \%$ (Figure 8 ). The $77 \mathrm{~K}$ Mössbauer spectrum of the latter sample showed first an external magnetic component which exhibits a complex hyperfine structure resulting typically from the superimposition of maghemite contribution and that of magnetite as below 
the Verwey transition. In addition, a magnetic feature (estimated at about 30\%) occurred at the center which can be assigned to metallic Fe species.

\section{Conclusions}

On the basis of all these findings, we can propose the reaction mechanism scheme depicted in Figure 9: i.e. the reaction of $\mathrm{NaBH}_{4}$ with most high index surfaces at its surface defects of polycrystalline magnetite can result in pre-nucleation cluster induced crystal formation of critical size of tiny $\mathrm{Fe}^{0}$ nanoparticles $(\sim 2 \mathrm{~nm})$ via its intermediate phase (i.e., $\left.\mathrm{FeO}\right)$. The newly formed elemental Fe nanoparticles are then attracted on top of mother magnetite by their instinctive magnetism and/or get assembled to grow to larger particle size. The various surface and catalytic investigations revealed that elemental Fe nanoparticles formed on the surface of polycrystalline magnetite after the reaction with $\mathrm{NaBH}_{4}$ are probably responsible for the sustainable catalytic activity. However, these newly generated elemental $\mathrm{Fe}$ nanoparticles cannot reduce $p$-NP without further $\mathrm{NaBH}_{4}$ addition. Indeed, the $p$-NP reduction only occurs when $\mathrm{NaBH}_{4}$ was added into the suspension during 10 times recycles in sequencing injection of $\mathrm{NaBH}_{4}$ and DIW, whereas kinetic rate constant increased as the reaction cycle increased (i.e., up to $\sim 0.131 \mathrm{~min}^{-1}$ ) (Figure S11). Furthermore, the catalytic activity of polycrystalline magnetite is preserved, which could overcome the deactivation problem generally encountered in other metallic nanoscale catalysts. As the catalytic reduction methods including dechlorination and hydrogenation of nitroaromatic compounds are often carried out under an atmosphere of $\mathrm{H}_{2}$ (hydrogen source), the experimental and theoretical results from this study can highlight the important dual role of $\mathrm{NaBH}_{4}$ : (i) acting as a hydrogen donor, and (ii) producing highly reactive nanoparticles on the surface of catalyst.

Although polycrystalline magnetite possesses much larger particle size (or lower surface area), it shows a remarkable catalytic activity compared to single crystalline magnetite. This counter-intuitive finding (because the greater reactivity of nanoscale materials is generally 
admitted) calls for more attention to the assessment of intrinsic reactivity of used materials in heterogeneous catalysis. As there is a growing interest in environmentally friendly catalytic processes based on magnetic solids, the remarkable catalytic recyclability of polycrystalline magnetite offers a strong potential for developing cheap and effective magnetic catalysts without use of noble precious metals. Furthermore, because synthesis methods for polycrystalline magnetite are becoming increasingly developped, ${ }^{53}$ we thus anticipate our findings to be a starting point for investigating other unknown properties of polycrystalline magnetite in other-disciplinary researches such as semiconductor, biomedicine, and environmental remediation.

\section{Supporting Information}

The Supporting Information is available free of charge on the ACS Publications website at DOI:

Details of the material characterization (i.e., XRD, SEM, Mössbauer, AFM, and TEM) and additional results for reduction of $\mathrm{p}-\mathrm{NP}$ by four different magnetite.

\section{Acknowledgments}

We would like to thank the "Région Bretagne" for financial support (Contract SAEDReSolEau (8256)) for the most of experiments and THEMIS for TEM experiments. We also acknowledge the support by the National Research Foundation of Korea (project no. 2016R1D1A1B03930142).

\section{References}


(1) Zaera, F. Nanostructured materials for applications in heterogeneous catalysis. Chem. Soc. Rev. 2013, 42, 2746-2762.

(2) Gawand, M. B.; Branco, P. S.; Varma, R. Nano-magnetite $\left(\mathrm{Fe}_{3} \mathrm{O}_{4}\right)$ as a support for recyclable catalysts in the development of sustainable methodologies. Chem. Soc. Rev. 2013, 42, 3371-3393.

(3) Wunder, S.; Polzer, F.; Lu, Y.; Mei, Y.; Ballauff, M. Kinetic analysis of catalytic reduction of 4-nitrophenol by metallic nanoparticles immobilized in spherical polyelectrolyte brushes. J. Phys. Chem. C 2010, 114, 8814-8820.

(4) Jana, S.; Ghosh, S. K.; Nath, S.; Pande, S.; Praharaj, S.; Panigrahi, S.; Basu, S.; Endo, T.; Pal, T. Synthesis of silver nanoshell-coated cationic polystyrene beads: A solid phase catalyst for the reduction of 4-nitrophenol. Appl. Catal., A: Gen. 2006, 313, 41-48.

(5) Lin, F-H.; Doong, R-A. Highly efficient reduction of 4-nitrophenol by heterostructured gold-magnetite nanocatalysts. Appl. Catal., A: Gen. 2014, 486, 32-41.

(6) Shin, K. S.; Cho, Y. K.; Choi, J-Y.; Kim, K. Facile synthesis of silver-deposited silanized magnetite nanoparticles and their application for catalytic reduction of nitrophenols. Appl. Catal., A: 2012, 413-414, 170-175.

(7) Li, J.; Liu, C.-y; Liu, Y. Au/graphene hydrogel: Synthesis, characterization and its use for catalytic reduction of 4-nitrophenol. J. Mater. Chem. 2012, 22, 8426-8430.

(8) Lin, F-H.; Doong, R-A. Bifunctional $\mathrm{Au}-\mathrm{Fe}_{3} \mathrm{O}_{4}$ heterostructures for magnetically recyclable catalysis of nitrophenol reduction. J. Phys. Chem. C 2011, 115, 6591-6598.

(9) Shin, H.; Jung, S.; Bae, S.; Kim, H.; Lee, W. Nitrate reduction mechanism on a Pd surface. Environ. Sci. Technol. 2014, 48, 12768-12774.

(10)Jung, S.; Bae, S.; Lee, W. Development of Pd-Cu/hematite catalyst for selective nitrate reduction. Environ. Sci. Technol. 2014, 48, 9651-9658.

(11)Jung, J.; Bae, S.; Lee, W. Nitrate reduction by maghemite supported Cu-Pd bimetallic catalyst. Appl. Catal. B- Environ. 2012, 127, 148-158. 
(12)Xu, Z. C.; Shen, C. M.; Hou, Y. L.; Gao, H. J.; Sun, S. S. Oleylamine as both reducing agent and stabilizer in a facile synthesis of magnetite nanoparticles. Chem. Mater. 2009, $21,1778-1780$.

(13)Rostamizadeh, S.; Shadjou, N.; Azad, M.; Jalali, N. $\left(\alpha-\mathrm{Fe}_{2} \mathrm{O}_{3}\right)-\mathrm{MCM}-41$ as a magnetically recoverable nanocatalyst for the synthesis of pyrazolo[4,3-c]pyridines at room temperature. Catal. Commun. 2012, 26, 218-224.

(14)Ramimoghadam, D.; Bagheri, S.; Hamid, S. B. A. Progress in electrochemical synthesis of magnetic iron oxide nanoparticles. J. Magn. Magn. Mater. 2014, 368, 207-229.

(15) Yang, C.; Wu, J.; Hou, Y. $\mathrm{Fe}_{3} \mathrm{O}_{4}$ nanostructures: synthesis, growth mechanism, properties and applications. Chem. Commun. 2011, 47, 5130-5141.

(16)Qi, H. P.; Chen, Q. W.; Wang, M. S.; Wen, M. H.; Xiong, J. Study of self-assembly of octahedral magnetite under an external magnetic field. J. Phys. Chem. C 2009, 113, $17301-17305$.

(17)Zhang, L. H.; Wu, J. J.; Liao, H. B.; Hou, Y. L.; Gao, S. Octahedral $\mathrm{Fe}_{3} \mathrm{O}_{4}$ nanoparticles and their assembled structures. Chem. Commun. 2009, 29, 4378-4380.

(18)Liu, F.; Cao, P. J.; Zhang, H. R.; Tian, J. F.; Xiao, C. W.; Shen, C. M.; Li, J. Q.; Gao. H. J. Novel nanopyramid arrays of magnetite. Adv. Mater. 2005, 17, 1893-1897.

(19) Gorski, C. A.; Nurmi, J. T.; Tratnyek, P. G.; Hofstetter, T. B.; Scherer, M. M. Redox behavior of magnetite: Implications for contaminant reduction. Environ. Sci. Technol. 2010, 44, 55-60.

(20)Cornell, R. M.; Schwertmann, U. The Iron Oxides: Structure, Properties, Reactions, Occurences and Uses, 2nd ed., pp. 185-407, Wiley-VCH Verlag GmbH \& Co. KGaA, Weinheim, FRG, Germany, 2003.

(21)Daniels, J. M.; Rosencwaig, A. Mössbauer spectroscopy of stoichiometric and nonstoichiometric magnetite. J. Phys. Chem. Solids 1969, 30, 1561-1571. 
(22)Hervés, P.; Perez-Lorenzo, M.; Liz-Marzan, L. M.; Dzubiella, J.; Lu, Y.; Ballauff, M. Catalysis by metallic nanoparticles in aqueous solution: Model reactions. Chem. Soc. Rev. 2012, 41, 5577- 5587.

(23)An, M.; Cui, J.; Wang. L. Magnetic recyclable nanocomposite catalysts with good dispersibility and high catalytic activity. J. Phys. Chem. C 2014, 118, 3062-3068.

(24)Zhang, P.; Li, R.; Huang, Y.; Chen, Q. A. Novel approach for the in situ synthesis of PtPd nanoalloys supported on $\mathrm{Fe}_{3} \mathrm{O}_{4} @ \mathrm{C}$ core-shell nanoparticles with enhanced catalytic activity for reduction reactions. ACS Appl. Mater. Interfaces 2014, 6, 2671- 2678.

(25)Song, J. M.; Zhang, S. S.; Yu, S. H. Multifunctional $\mathrm{Co}_{0.85} \mathrm{Se}_{-} \mathrm{Fe}_{3} \mathrm{O}_{4}$ nanocomposites: controlled synthesis and their enhanced performances for efficient hydrogenation of $p$ nitrophenol and adsorbents. Small 2014, 10, 717-724.

(26)Wang, Q.; Jia, W.; Liu, B.; Dong, A.; Gong, X.; Li, C.; Jing, P.; Li, Y.; Xu, G.; Zhang, J. Hierarchical structure based on $\mathrm{Pd}(\mathrm{Au})$ nanoparticles grafted onto magnetite cores and double layered shells: enhanced activity for catalytic applications. J Mater Chem A 2013, $1,12732-12741$.

(27)Xu, R.; Bi, H.; He, G.; Zhu, J.; Chen, H. Synthesis of $\mathrm{Cu}-\mathrm{Fe}_{3} \mathrm{O}_{4} @$ graphene composite: a magnetically separable and efficient catalyst for the reduction of 4-nitrophenol. Mater. Res. Bull. 2014, 57, 190-196.

(28)Du, X.; He, J.; Zhu, J.; Sun, L.; An, S. Ag-deposited silica-coated $\mathrm{Fe}_{3} \mathrm{O}_{4}$ magnetic nanoparticles catalyzed reduction of p-nitrophenol. Appl. Surf. Sci. 2012, 258, 2717-2723.

(29)Bae, S. \& Hanna, K. Reactivity of nanoscale zero valent iron in unbuffered systems: Effect of pH and Fe(II) dissolution. Environ. Sci. Technol. 2015, 49, 10536-10543.

(30)Bae, S.; Gim, S.; Kim, H; Hanna, K. Effect of $\mathrm{NaBH}_{4}$ on properties of nanoscale zerovalent iron and its catalytic activity for reduction of $p$-nitrophenol. Appl. Catal. BEnviron. 2016, 127, 148-158. 
(31)Usman, M.; Abdelmoula, M.; Hanna, K.; Grégoire, B.; Faure, P.; Ruby, C. Fe ${ }^{\mathrm{II}}$ induced mineralogical transformations of ferric oxyhydroxides into magnetite of variable stoichiometry and morphology. J. Solid State Chem. 2012, 194, 328-335.

(32) Stookey, L. L. Ferrozine-A new spectrophotometric reagent for iron. Anal. Chem. 1970, $42,779-781$.

(33)Bae, S.; Lee, W. Influence of riboflavin on nanoscale zero-valent iron reactivity during the degradation of carbon tetrachloride. Environ. Sci. Technol. 2014, 48, 2368-2376.

(34)Rodriguez-Carvajal, J. Recent advances in magnetic-structure determination by neutron powder diffraction. Physica B 1993, 192, 55-69.

(35)Rodriguez-Carvajal, J.; Roisnel, T. Line broadening analysis using Fullprof: Determination of microstructural properties. Materials Science Forum 2004, 443-444, $123-126$.

(36)Kresse J. G.; Furthmuller. J. Efficient iterative schemes for ab initio total-energy calculations using a plane-wave basis set. Phys. Rev. B 1996, 54, 11169-11186.

(37)Perdew, J. P.; Burke, K.; Ernzerhof, M. Generalized gradient approximation made simple. Phys. Rev. Lett. 1996, 77, 3865-3868.

(38) Gorski, C. A.; Scherer, M. M. Determination of nanoparticulate magnetite stoichiometry by Mössbauer spectroscopy, acidic dissolution, and powder X-ray diffraction: A critical review. Am. Mineral. 2010, 95, 1017-1026.

(39)Kim, W.; Suh, C.-Y.; Cho, S.-W.; Roh, K.-M.; Kwon, H.; Song, K.; Shon. I.-J. A new method for the identification and quantification of magnetite-maghemite mixture using conventional X-ray diffraction technique. Talanta 2012, 94, 348- 352.

(40)Kong, X. K.; Sun, Z. Y.; Chen, M.; Chen, Q. W. Metal-free catalytic reduction of 4nitrophenol to 4-aminophenol by N-doped graphene. Energy Environ. Sci. 2013, 6, 32603266 . 
(41)Lara, L. R.; Zottis, A. D.; Elias, W. C.; Faggion, D.; de Campos, C. E. M.; Acuña, J. J. S.; Domingos, J. B. The catalytic evaluation of in situ grown Pd nanoparticles on the surface of $\mathrm{Fe}_{3} \mathrm{O}_{4} @$ dextran particles in the p-nitrophenol reduction reaction. $R S C A d v . \mathbf{2 0 1 5}, 5$, $8289-8296$.

(42) Gu, S.; Wunder, S.; Lu, Y.; Ballauff, M. Kinetic analysis of the catalytic reduction of 4nitrophenol by metallic nanoparticles. J. Phys. Chem. C 2014, 118, 18618-18625.

(43)Wang, Q. L.; Kanel, S. R.; Park, H.; Ryu, A.; Choi. H. Controllable synthesis, characterization, and magnetic properties of nanoscale zerovalent iron with specific high Brunauer-Emmett-Teller surface area. J. Nanopart. Res. 2009, 11, 749-755.

(44)Kashchiev, D. Nucleation: Basic Theory with Applications, ButterworthHeinemann, Oxford, 2000.

(45)Banfield, J. F.; Welch, S. A.; Zhang, H.; Ebert, T. T.; Penn, R. L. Aggregation-based crystal growth and microstructure development in natural iron oxyhydroxide biomineralization products. Science 2000, 289, 751-754.

(46)Hua, Q.; Huang, W. Chemical etching induced shape change of magnetite microcrystals. J. Mater. Chem. 2008, 18, 4286-4290.

(47)Bell, R. P. The theory of reactions involving proton transfers. Proc. R. Soc. London, Ser. A 1936, 154, 414-429.

(48)Evans, M. G.; Polanyi, M. Further considerations on the thermodynamics of chemical equilibria and reaction rates. Trans. Faraday Soc. 1936, 32, 1333-1360.

(49) Trasatti, S. Interfacial behavior of non-aqueous solvents. Electrochim. Acta 1987, 31, $843-850$.

(50)Zhang, P.; Sui, Y.; Xiao, G.; Wang, Y.; Wang, C.; Liu, B.; Zou, G.; Zou, B. Facile fabrication of faceted copper nanocrystals with high catalytic activity for p-nitrophenol reduction. J. Mater. Chem. A 2013, 1, 1632- 1638. 
(51)Wu, Y.-G.; Wen, M.; Wu, Q.-S.; Fang, H. Ni/graphene nanostructure and its electronenhanced catalytic action for hydrogenation reaction of nitrophenol. J. Phys. Chem. C 2014, 118, 6307-6313.

(52)Kojima, Y.; Suzuki, K.; Fukumoto, K.; Sasaki, M.; Yamamoto, T.; Kawai, Y.; Hayashi, H. Hydrogen generation using sodium borohydride solution and metal catalyst coated on metal oxide. Int. J. Hydrogen Energy 2002, 27, 1029-1034.

(53)Mantovan, R.; Lamperti, A.; Georgieva, M.; Tallarida, G.; Fanciulli, M. CVD synthesis of polycrystalline magnetite thin films: structural, magnetic and magnetotransport properties. J. Phys. D: Appl. Phys. 2010, 43, 065002-1. 


\section{Figures}

Figure 1. TEM images and SAED patterns of four different magnetite samples: (a and b) M 1, (c and d) M2, (e and f) M3, and (g and h) M4.

Figure 2. Reduction kinetics of $\mathrm{p}-\mathrm{NP}$ by $\mathrm{M} 4-\mathrm{NaBH}_{4}$ system: (a) Effect of $\mathrm{NaBH}_{4}$ concentration on the reduction of $p$-NP showing the pseudo-zero-order reaction kinetics and (b) change in $\mathrm{k}_{\mathrm{obs}}$ with respect to the $\mathrm{NaBH}_{4}$ concentration.

Figure 3. TEM results for M4 after the reaction: (a) TEM images after the $1^{\text {st }}$ reaction of M4 showing both (b) the amorphous SAED pattern of spherical shape of nanoparticles (c and d) and (e) the magnetite SAED pattern of original M4. (f) STEM Bright field image and EDX mapping showing the elemental distribution on the surface.

Figure 4. AFM results before and after the reaction: AFM images of M4 (a) before and (b) after the reaction and their 3D topographic images (c and d). (e) The different topography deviation of M4 (indicated by arrow in (a) and (b)) showing the evolution of spikes and formation of cracks after the reaction.

Figure 5. HR-TEM results for M4 after the reaction: TEM images show (a) the crack formation and (b) small nanoparticles gathering on top of M4 surface. (c and d) The inner structure of intermediate phase revealed both the magnetite and wüstite SAD patterns. (e) Final structure of M4 after the reaction.

Figure 6. Results of DFT calculation: the results showed $\mathrm{BH}_{3}$ binding energies $\left(\Delta \mathrm{E}_{b}{ }^{\mathrm{BH} 3}\right)$, BFe binding distances, and electrochemical reduction potential for leaching $\mathrm{Fe}$ out from the 
surface $\left(\varepsilon^{0}\right.$ Fe vs. SHE), which are calculated for various magnetite slab models of $(2 \times 1)$ $\mathrm{Fe}_{3} \mathrm{O}_{4}(111),(2 \times 2) \mathrm{Fe}_{3} \mathrm{O}_{4}(220),(2 \times 3) \mathrm{Fe}_{3} \mathrm{O}_{4}(311),(3 \times 1) \mathrm{Fe}_{3} \mathrm{O}_{4}(400),(4 \times 1) \mathrm{Fe}_{3} \mathrm{O}_{4}(422)$ and $(8 \times 1) \mathrm{Fe}_{3} \mathrm{O}_{4}(511)$ surfaces. $n=3$ as formal charge of exposed Fe atom was chosen when $\varepsilon_{\mathrm{Fe}}^{0}$ is calculated using Eq. (1).

Figure 7. Recycling test: (a) Reduction kinetics of $p$-NP by M4 with $\mathrm{NaBH}_{4}$ during the 10 time recycling test, (b) pseudo-first-order kinetics from $2^{\text {nd }}$ cycle and their mean $\mathrm{k}_{\mathrm{obs}}$ value (green line) with standard deviation (shaded area), and (c) the conversion efficiency after finishing each cycle.

Figure 8. $300 \mathrm{~K}$ Mössbauer spectra recorded on the as-prepared M4 and M4 submitted to different cycling treatments and $77 \mathrm{~K}$ Mössbauer spectrum on M4 submitted to 10 times cycling treatments; red and blue curves correspond to ideal magnetite and maghemite magnetic components at $300 \mathrm{~K}$, respectively, while the green curve is ascribed to the last component as described in the text.

Figure 9. (a) Conceptual atomic diagram showing the enhanced disintegration of magnetite by $\mathrm{NaBH}_{4}$ as the index surface increases and (b) catalytic mechanism proposed by this study. Red, purple, orange, cyan, white, grey circles and sticks denote oxygen, iron, boron, sodium, hydrogen, carbon, respectively. 


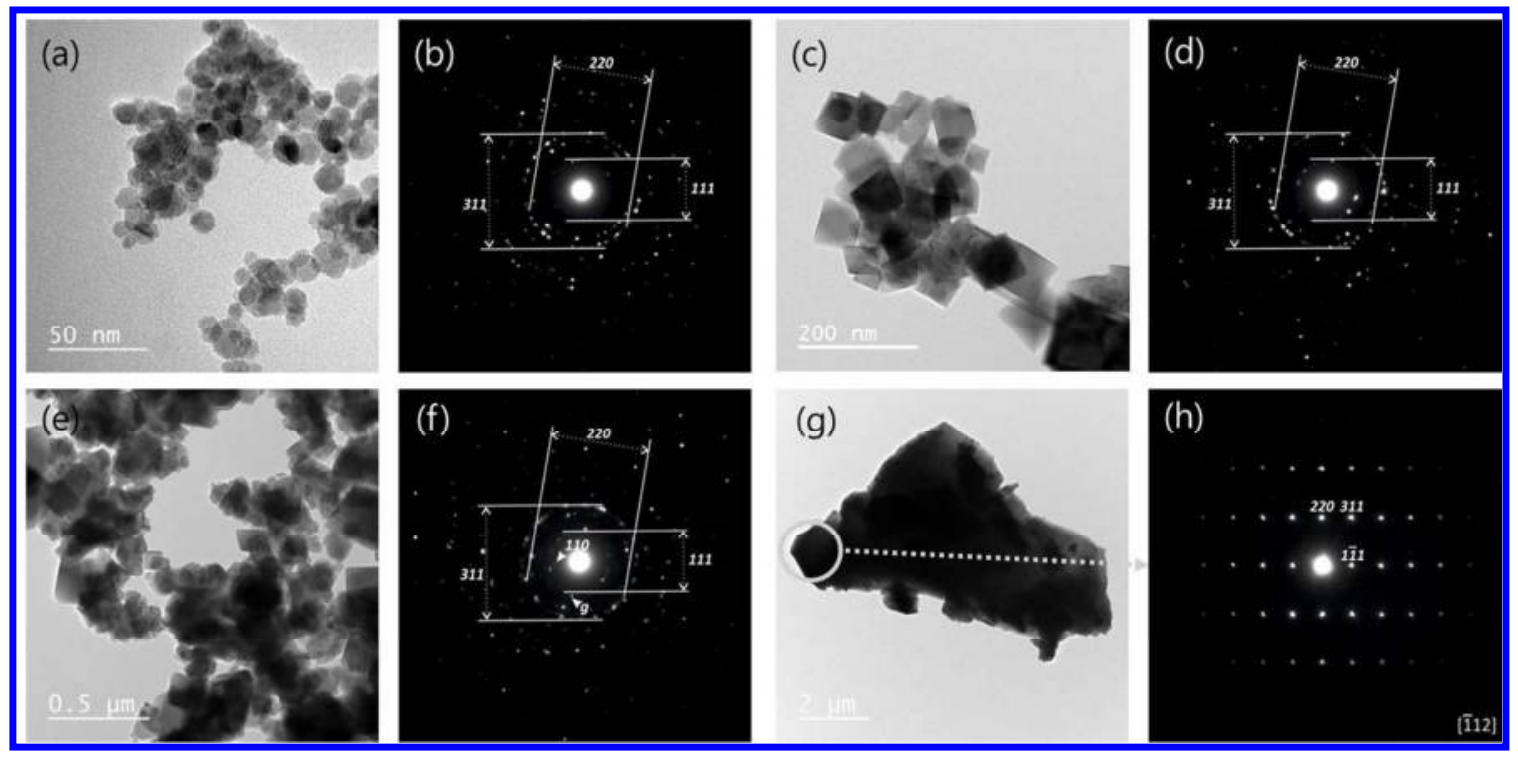

Figure 1 

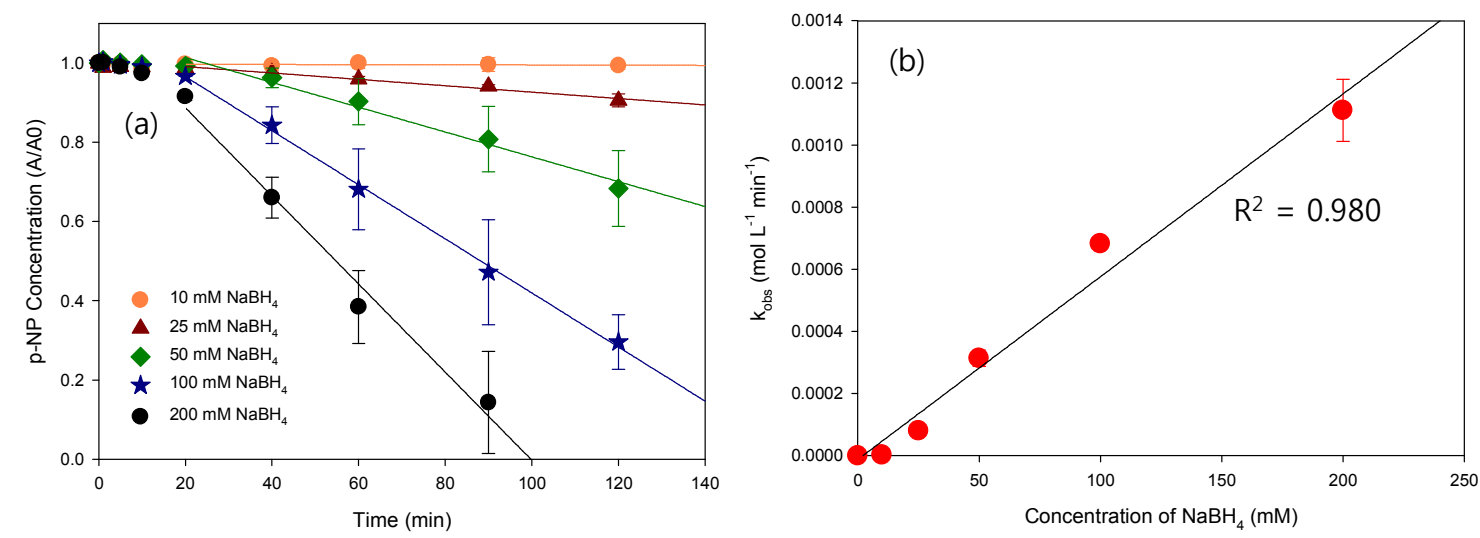

Figure 2 


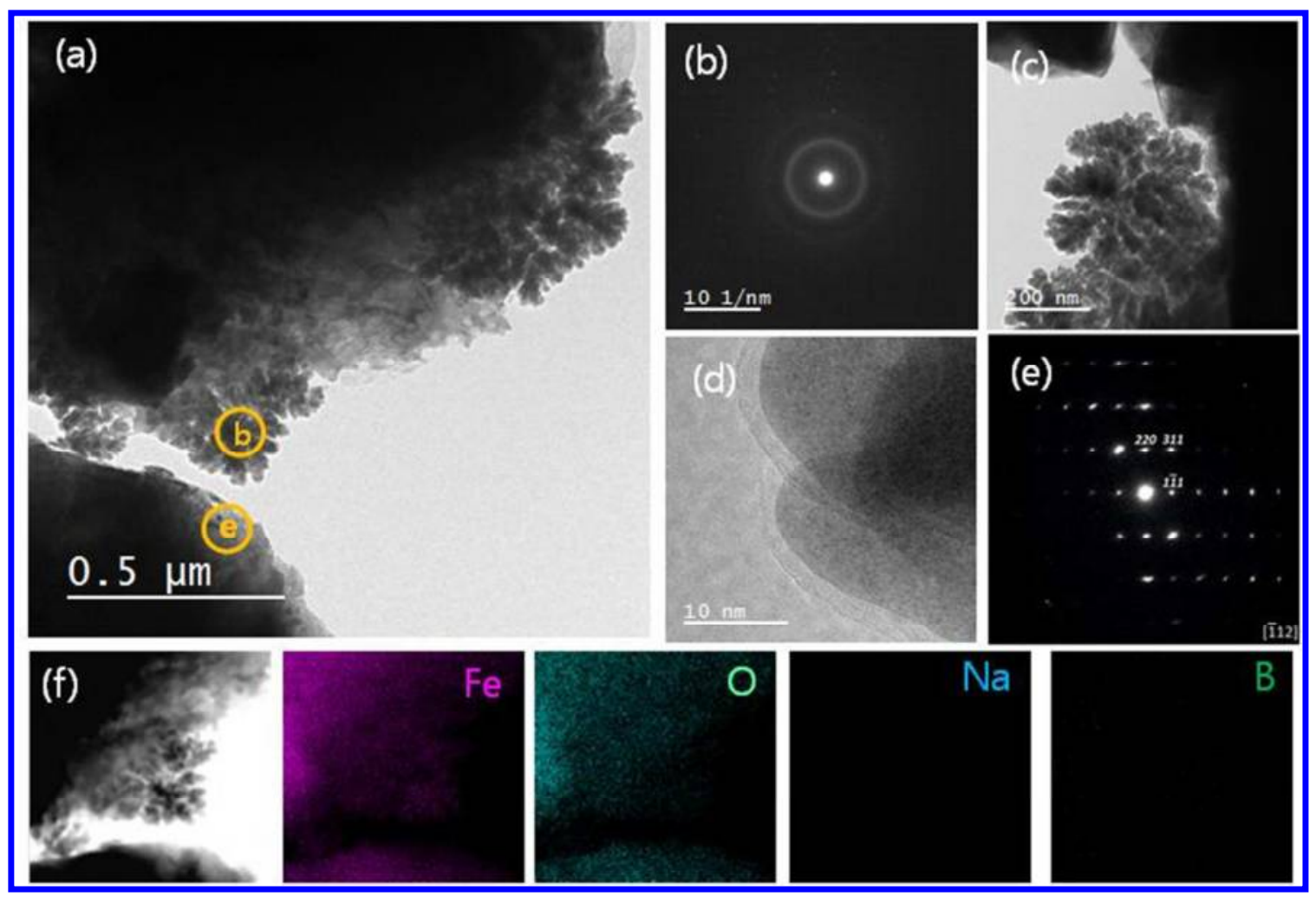

Figure 3 


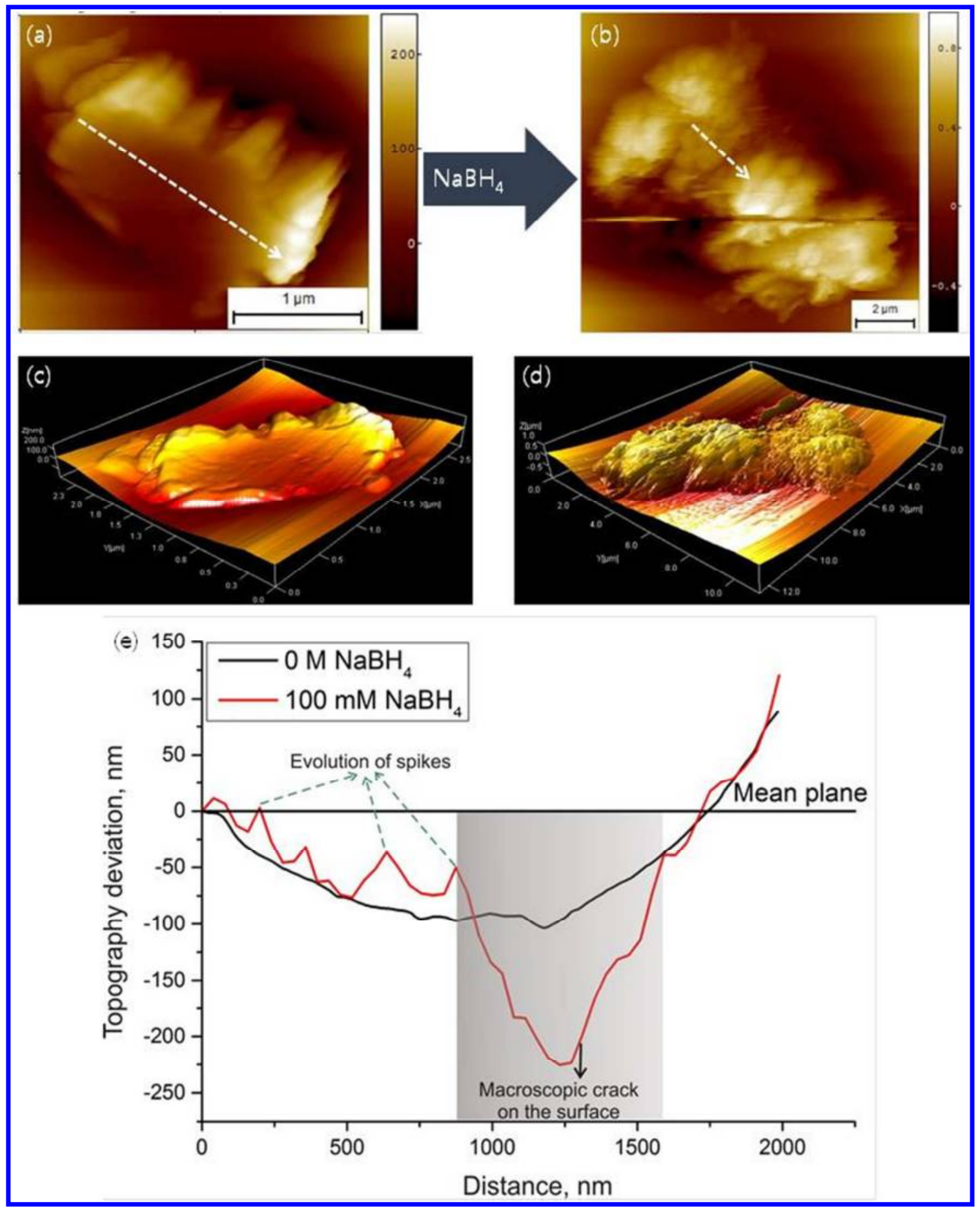

Figure 4 


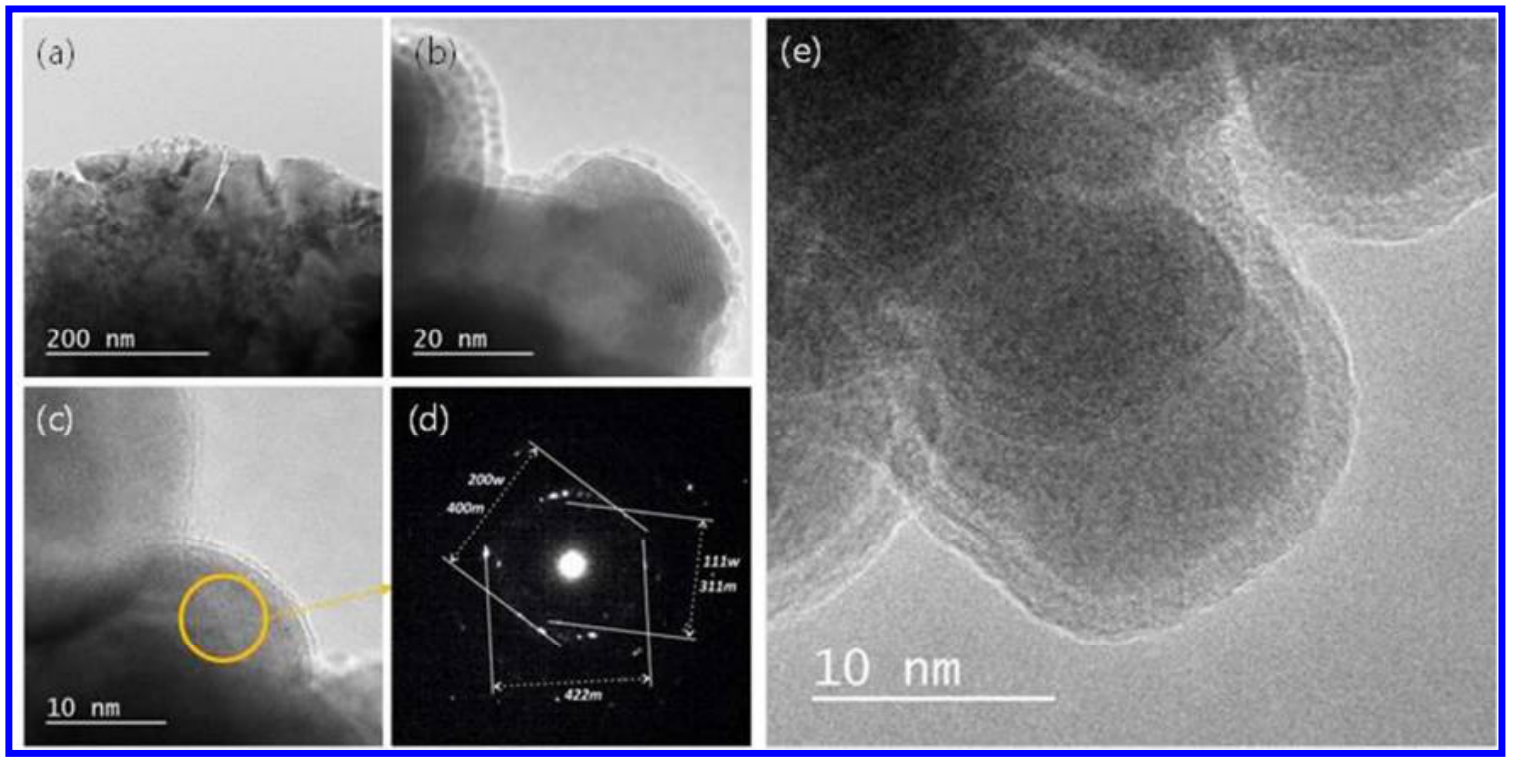

Figure 5 


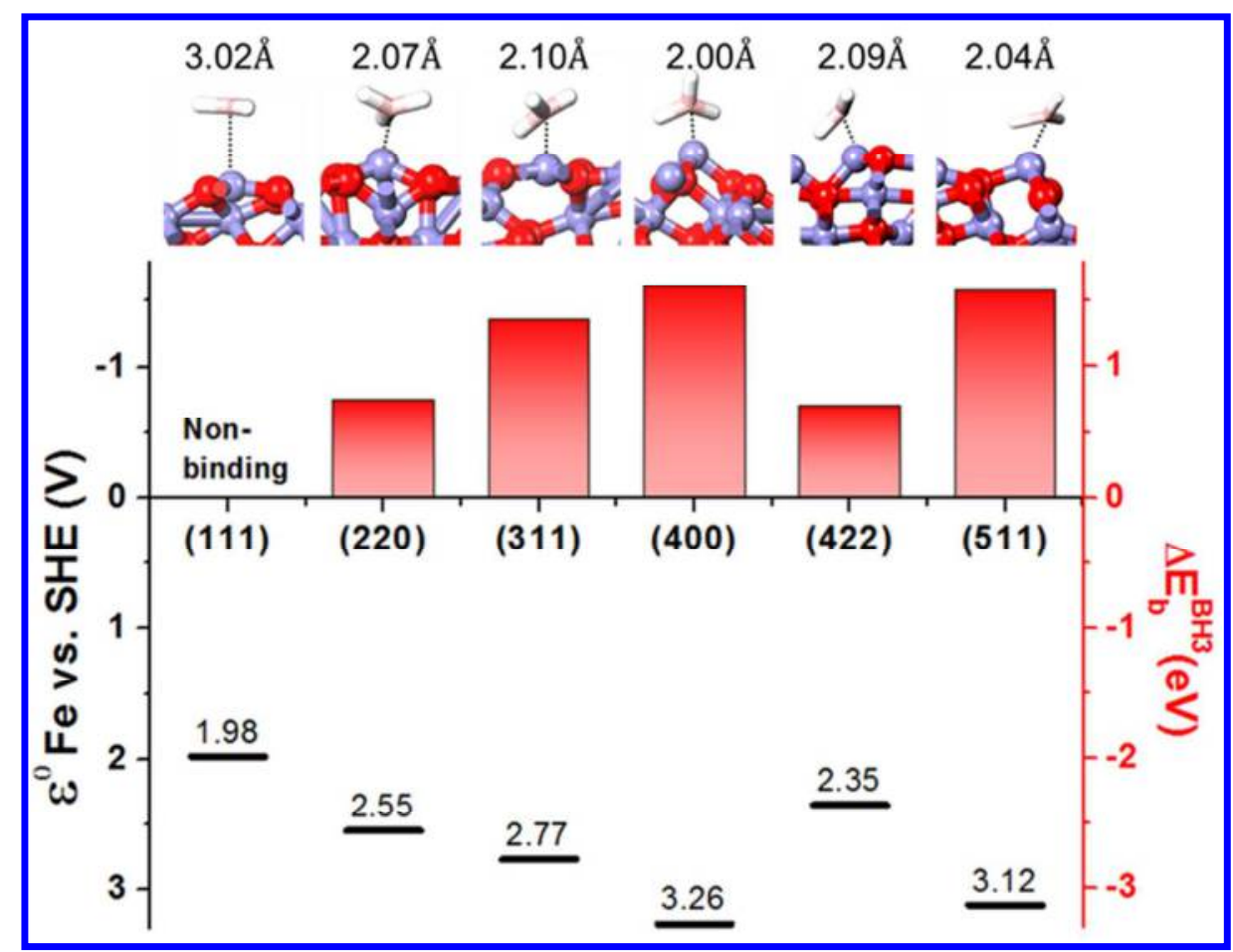

Figure 6 

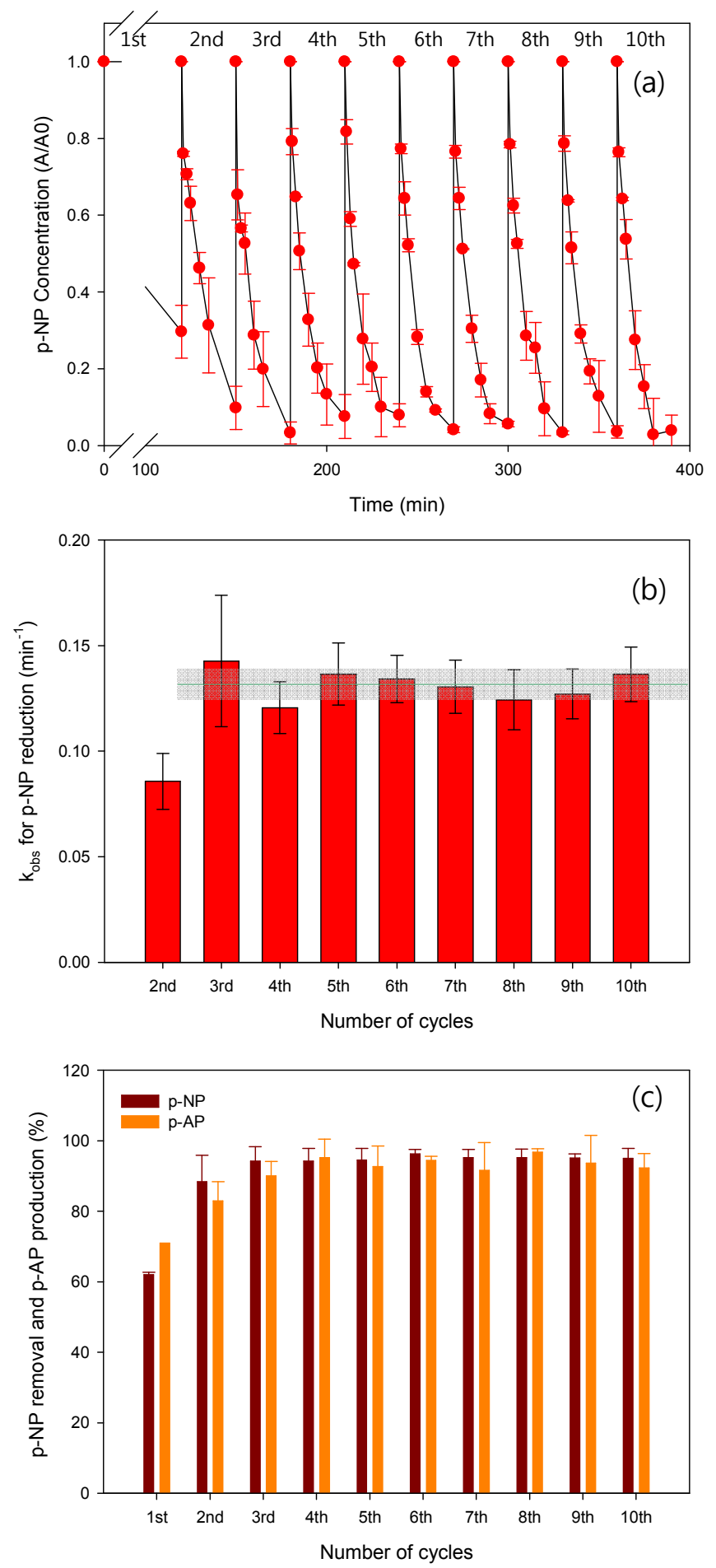

Figure 7 


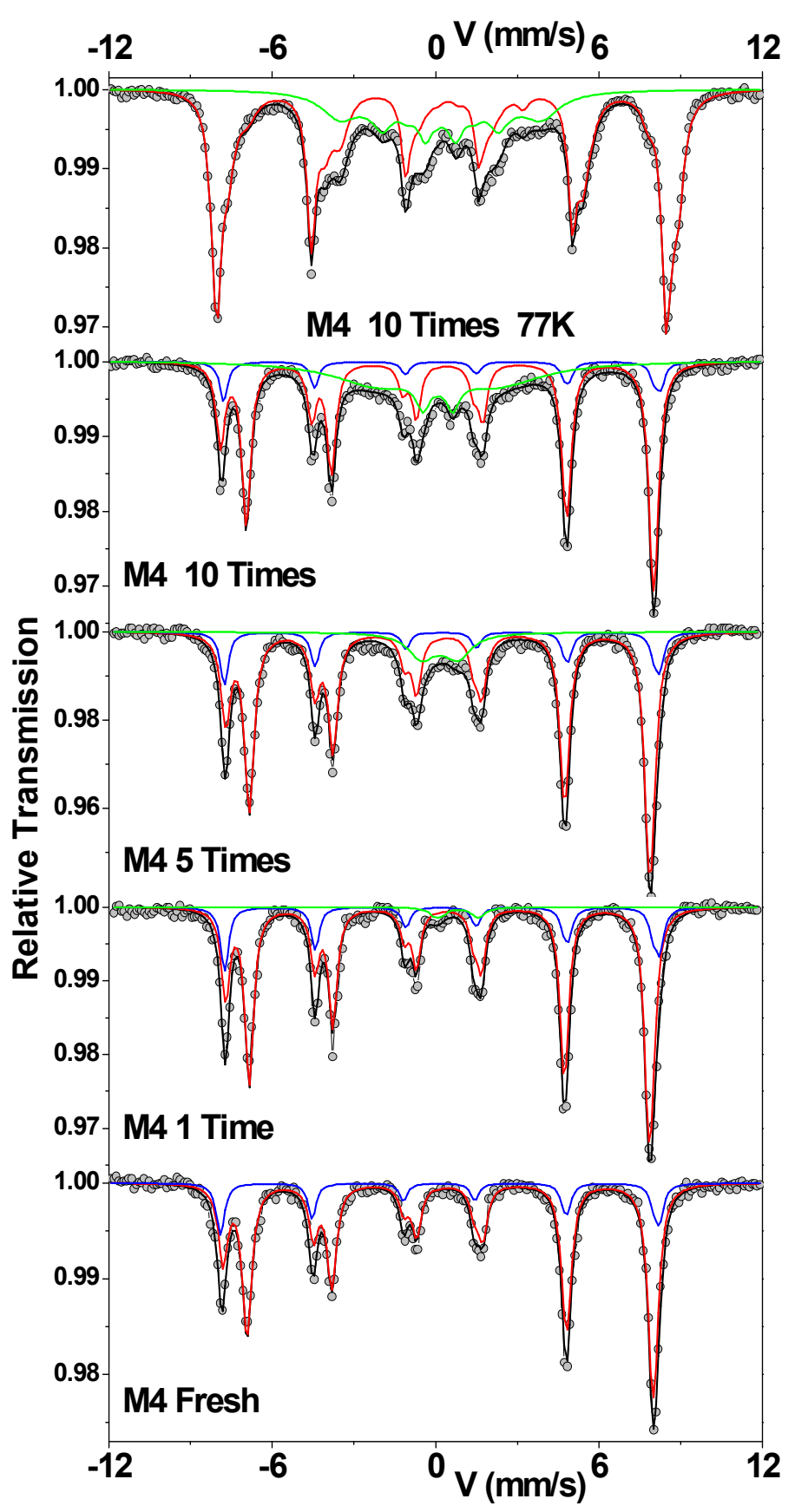

Figure 8 


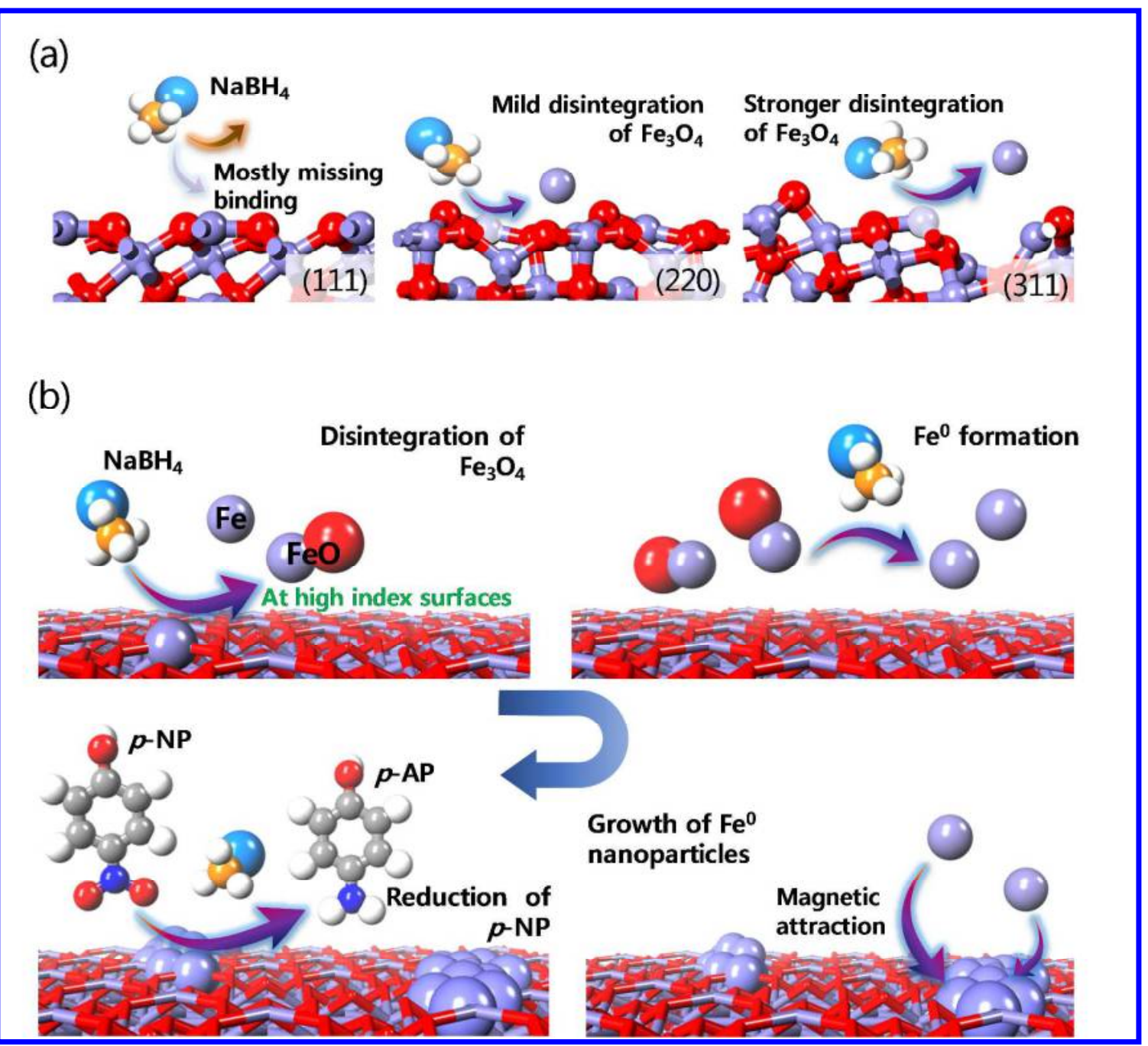

Figure 9 


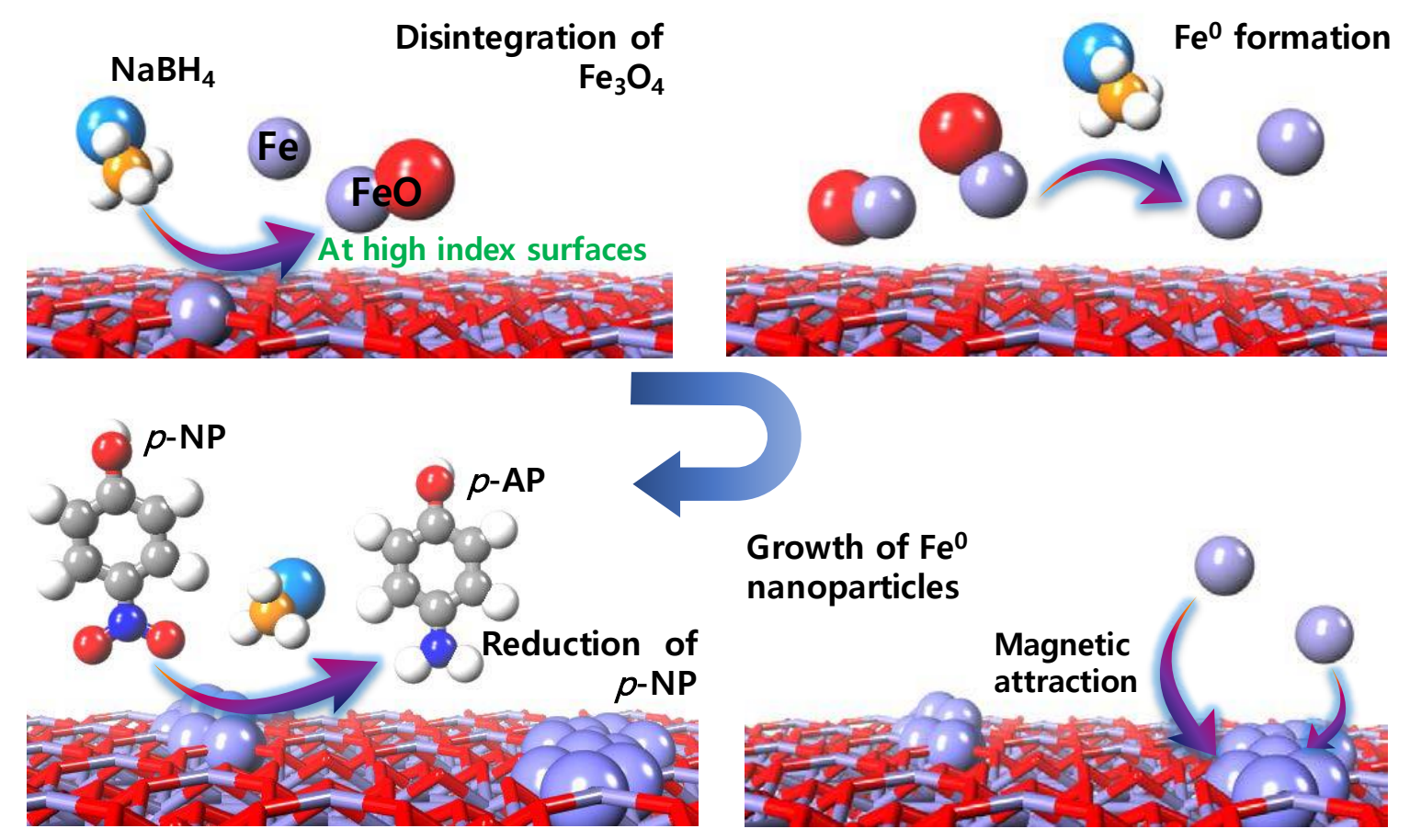

